\title{
LXIX. The $\alpha$ particles of uranium and thorium
}

\section{W.H. Bragg M.A.}

To cite this article: W.H. Bragg M.A. (1906) LXIX. The $\alpha$ particles of uranium and thorium , Philosophical Magazine Series 6, 11:66, 754-768, DOI: 10.1080/14786440609463495

To link to this article: http://dx.doi.org/10.1080/14786440609463495

曲 Published online: 16 Apr 2009.

Submit your article to this journal $2 \pi$

Џll Article views: 4

Q View related articles $₫$

4 Citing articles: 2 View citing articles 준 


\section{$\left[\begin{array}{ll}754 & ]\end{array}\right.$}

LXIX. The a Particles of Uranium and Thorium. By W. H. BragG, M.A., Elder Professor of Mathematics and Physics in the University of Adelaide*.

THIS paper is divided into two parts. The first contains a discussion of the magnitude of the ionization current due to a layer of radioactive material scattered on the floor of an ionization-chamber, and covered by a uniform sheet of metal foil. The result is expressed in a formula which is somewhat complicated in its general form, but is capable of simplification under suitable conditions. Account is taken of the variation of ionization with velocity. The second contains an account of experiments which show:-

(a) That the values of the current in various cases, calculated from the formula, agree very well with the results of observation.

(b) That the ranges of the $a$ particles of uranium and thorium are very nearly, perhaps exactly, equal to the range of the $\alpha$ particle of radium.

(c) That the rate at which thorium atoms break down is nearly $\cdot 19$ of the similar rate for uranium.

\section{PART I.}

The method which was used by Mr. Kleeman and myself in the determination of the ranges of the $\alpha$ particles emitted by radium and its products does not lend itself to the corresponding determinations in the cases of uranium and thorium. It is a necessary feature of the method that all $\alpha$ particles except those moving normally to the horizontal layer of radioactive material should be prevented from reaching the ionization-chamber, below which the radium is placed. This is done by the use of a bundle of vertical tubes which stop all $a$ particles other than those moving in the desired direction. But this limitation diminishes very greatly the number of effective $\alpha$ particles, and in the cases of uranium and thorium the effect is reduced below the limits of convenient measurement. This is the case even when a large surface of radioactive material is employed. In order to determine the ranges of uranium and thorium another method must be devised.

I have therefore calculated the ionization due to a radioactive layer over which a screen has been placed. The result is a function of the relation of the stopping power of the

* Communicated by the Author. 
screen to the range of the particle : so that if experiment is made the one can be found in terms of the other. The stopping power of the screen may be made the subject of a direct measurement, and so the range of the $a$ particle can be determined. I find it better, however, to compare the range of the uranium or thorium $\alpha$ particle with that of radium, working the experiment by a substitution method : for the range in the case of radium is known with some accuracy, and the method itself is accurate enough when employed in comparing ranges, but a little uncertain in its application to direct determinations, as will be explained later.

Experiments of this kind have already been made by several observers, notably by Professor Rutherford and Miss Brooks (Phil. Mag. July 1900). But at the time when they were made it was believed that the " $\alpha$ rays" were absorbed according to an exponential law: it was not known that each a particle possessed a definite range or penetrating power. Consequently the results were not in all cases expressed in such a way as to render them available for the calculation of the range. I have therefore found it convenient to repeat them.

In the following theoretical treatment of the question three cases are considered :-

(a) When the layer of radioactive material is so thick that the $a$ rays from the bottom of it are unable to reach the air above : such a thickness is of the order $.002 \mathrm{~cm}$.

(b) When the layer is extremely thin.

(c) When the layer is thicker than in (b) but not so thick as in $(a)$.

The first and second are really special cases of the third. Uranium and thorium are conveniently treated under cuse $(a)$; radium under $(c)$; and the induced activities under $(b)$. CASE (a): Thick layer of radioactive material over which a sheet of absorbing material is laid.-Let the surface of the radioactive material be of unit area : the full range of the $\alpha$ particle in air be $\mathbf{R}$, and the range lost by passing normally through the absorbing sheet be $\mathrm{D}$.

Let the stopping power of the radioactive material per radioactive atom be $s$. This means that if an $a$ particle passes, parallel to the axis, along a cylinder containing only as much matter as goes with one radioactive atom of the radioactive material, the loss of range is, on the average of a great number of such passages, $s$ times the loss when an average air molecule is substituted for the other matter. The length of the cylinder is, of course, immaterial. 
The $\alpha$ particles, when they emerge into the air, will penetrate to distances depending on the quantity of matter traversed before emerging. Consider in the first place all those whose ranges in air after emergence lie between $r$ and $r+d r$. These move at various inclinations to the surface: the number emerging at any inclination depends on that inclination, and may be reckoned as follows.

Consider only those whose inclinations to the normal lie between $\theta$ and $\theta+d \theta$. All these come from a layer of a certain thickness at a certain depth below the surface. The depth does not concern us, but the thickness does, for we need to know the number of radioactive atoms in the layer.

Let $n$ be the number of radioactive atoms in a cub. cent. of the material, $n_{0}$ the number of molecules in a cub. cent. of air.

An $\alpha$ particle loses the same range in traversing a distance $\delta r$ in air, as in traversing a distance $n_{0} \delta r / n s$ in the radioactive

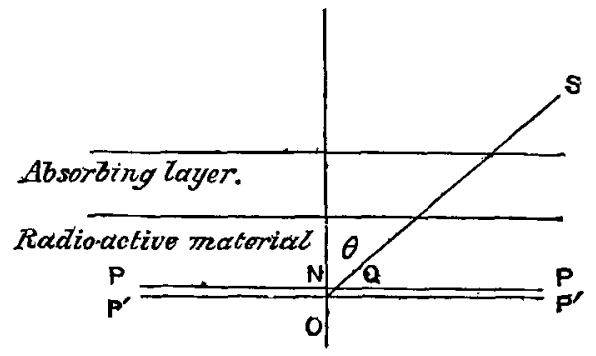

material. Hence if $\mathrm{PP}^{\prime}$ is the layer in question, $\mathrm{O}$ the radioactive atom, $O S$ the course of the a particle, we have $\mathrm{OQ}=n_{0} \delta r / n s$ and $\mathrm{ON}=n_{0} \delta r \cos \theta / n s$. This last expression is also the volume of the layer from which the $\alpha$ particles come, since we are considering unit area of the material ; and therefore the number of radioactive atoms in it is $n_{0} \delta r \cos \theta / s$.

Let each atom emit $\mathrm{N} \propto$ particles per second. $\mathrm{N}$ is a very small fraction. Then the number emitted by each particle between the inclinations $\theta$ and $\theta+d \theta$ is

$$
\mathrm{N} .2 \pi \sin \theta \cdot \delta \theta / 4 \pi=\mathrm{N} \sin \theta \cdot \delta \theta / 2 .
$$

Hence finally the number of a particles whose ranges in air after emergence lie between $r$ and $r+\delta r$, and which have inclinations to the normal varying from $\theta$ to $\theta+\delta \theta$, is

$$
\mathrm{N} \sin \theta \cdot n_{0} \cos \theta \delta r \delta \theta / 2 s \text {. }
$$

The limits of $\theta$ are zero and such a value of $\theta$ that the $\alpha$ particles which come from the very surface of the radioactive 
material and move at this inclination to the normal have a range $r$ in the air after penetrating the absorbing sheet.

This value of $\theta$ is given by $\mathrm{D} \sec \theta+r=\mathrm{R}$.

Integrating between these limits we find that the total number of $\alpha$ particles whose ranges lie between $r$ and $r+\delta r$

$$
=\frac{\mathrm{N} n_{0}}{4 s}\left\{1-\frac{\mathrm{D}^{2}}{(\mathrm{R}-r)^{2}}\right\} \delta r .
$$

Each of these moves a distance $r$ through the air of the ionization chamber before it ceases to ionize. Now I have shown (Phil. Mag. Nov. 1905) that the $\alpha$ particle spends energy on ionization at a rate which is inversely proportional to the energy which it possesses; so that we may say that $\delta e=k \delta r / e$, where $e$ is the energy of the particle and $\delta e$ the energy spent in traversing a distance $\delta r$. Hence we find that $e \propto \sqrt{ }(r+c)$, where $c$ is a constant. The value of the latter I have shown (loc. cit.) to be 1.33. Hence the ionization produced by the $\alpha$ particle in the last $r \mathrm{~cm}$. before it ceases to ionize may be written

$$
l(\sqrt{r+1 \cdot 33}-\sqrt{1 \cdot 33)} .
$$

Even if this expression should prove to be based on imperfect theory, it nevertheless expresses the actual fact very nearly.

Finally, therefore, the whole ionization $(=i)$

$$
=\frac{\mathrm{N} l n_{0}}{4 s} \int_{0}^{\mathrm{R}-\mathrm{D}}\left\{1-\frac{\mathrm{D}^{2}}{(\mathrm{R}-r)^{2}}\right\}(\sqrt{r+d}-\sqrt{d}) d r,
$$

the proper limits being given to $r$ in the integral.

After some reduction the value of this integral can be found to be

$$
\begin{aligned}
\frac{\mathrm{N} l n_{0}}{4 s}\left\{\frac{2}{3}(\mathrm{R}-\mathrm{D}+d)^{\frac{3}{3}}-\frac{2}{3} d^{\frac{3}{2}}-\mathrm{R} \sqrt{\bar{d}}-\mathrm{D} \sqrt{\mathrm{R}+\bar{d}-\overline{\mathrm{D}}}+2 \mathrm{D} \sqrt{d}\right. \\
\left.+\frac{\mathrm{D}^{2}}{\sqrt{\mathrm{R}+} d} \log \frac{\sqrt{\mathrm{R}(\sqrt{\mathrm{R}+d}+\sqrt{\mathrm{R}+d-\bar{D}})}}{\sqrt{\overline{\mathrm{D}}(\sqrt{\mathrm{R}+d}+\sqrt{\bar{d}})}}\right\} .
\end{aligned}
$$

If we put $D=0$, we obtain the value of the current (I) when the radioactive material is uncovered, viz.:

$$
\mathrm{I}=\frac{\mathrm{N} l n_{0}}{4 s}\left\{\frac{2}{3}(\mathrm{R}+d)^{\frac{3}{2}}-\frac{2}{3} d^{\frac{3}{2}}-\mathrm{R} \sqrt{d}\right\} .
$$

Simpler formulæ may be found by neglecting the variation of ionization with velocity. If we put the ionization due to 
traversing $r \mathrm{~cm}$. equal to $l^{\prime} r$, we find that

$$
i=\frac{\mathrm{N} l^{\prime} n_{\mathrm{o}}}{8 s}\left\{(\mathrm{R}-\mathrm{D})(\mathrm{R}-3 \mathrm{D})+2 \mathrm{D}^{2} \log \frac{\mathrm{R}}{\mathrm{D}}\right\},
$$

and $\quad \mathrm{I}=\frac{\mathrm{N} l^{\prime} n_{0}}{8 s} \mathrm{R}^{2}$.

Curves may be plotted from these formulæ giving the relation between $i / \mathrm{I}$ and $\mathrm{D} / \mathrm{R}$. In the case of the latter

Fig. 1.

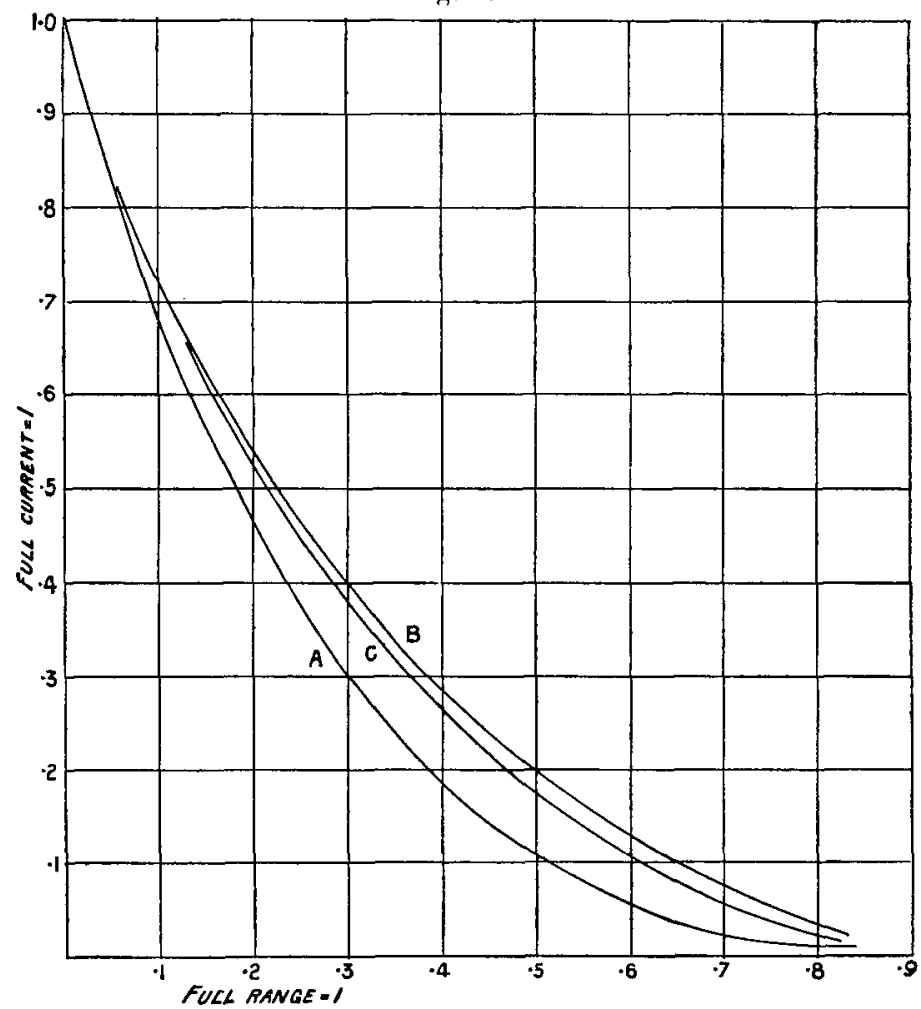

formula the form of the curve is independent of the value of $\mathrm{R}$; but in the more accurate formula it is not. Actual trial shows, however, that the curve in this case shifts very little when the value of $R$ is altered, and always lies close to that given by the simpler formula. In the interpretation of the experiments with uranium and thorium, I have used the curve A (see fig. 1) in which $R=3$ : it gives results of 
a Particles of Uranium and Thorium.

sufficient accuracy, though the actual value of the range of the $a$ particle from these substances is nearly 3.5 .

The curve is plotted from the following figures:-

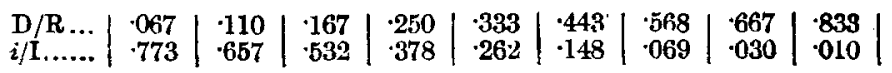

CASE (b). Very thin layer of radioactive material.-Let D be the air equivalent of the layer of radioactive material, $i$. $e$. the loss of range which an $a$ particle would experience in crossing the layer normally.

The limits of $\theta$ are now $\theta_{1}+\theta_{2}$, where

$$
\mathrm{D} \sec \theta_{1}+r=\mathrm{R} \text { and }\left(\mathrm{D}+\mathrm{D}^{\prime}\right) \sec \theta_{2}+r=\mathrm{R} \text {. }
$$

Hence the total number of particles whose ranges lie between $r$ and $r+\delta r^{\bullet}$ is

$$
\begin{aligned}
\frac{\mathrm{N} n_{0}}{4 s} & \left\{\frac{\left(\mathrm{D}+\mathrm{D}^{\prime}\right)^{2}}{(\mathrm{R}-r)^{2}}-\frac{\mathrm{D}^{2}}{(\mathrm{R}-r)^{2}}\right\} \delta r \\
& =\frac{\mathrm{N} n_{\mathrm{n}} \mathrm{DD}}{2 s} \frac{\delta r}{(\mathrm{R}-r)^{2}}, \text { neglecting } \mathrm{D}^{\prime 2} .
\end{aligned}
$$

Hence the ionization (i)

$$
\begin{gathered}
=\frac{\mathrm{N} \ln n_{0}}{2 s} \int_{0}^{\mathrm{R}-\mathrm{D}} \mathrm{DD}^{\prime} \frac{\sqrt{r+d}-\sqrt{d}}{(\mathrm{R}-r)^{2}} d r \\
=\frac{\mathrm{N} \ln n_{0} \mathrm{D}^{\prime}}{2 s}\left\{\sqrt{\mathrm{R}+d-\mathrm{D}}-\sqrt{d}-\frac{\mathrm{D}}{\sqrt{\mathrm{R}+d}} \log \frac{\sqrt{\mathrm{R}}(\sqrt{\mathrm{R}+d}+\sqrt{\mathrm{R}+d-\mathrm{D})}}{\sqrt{\overline{\mathrm{D}}(\sqrt{\mathrm{R}+d}+\sqrt{\bar{d}})}\} ;}\right. \\
\text { and when } \mathrm{D}=0 \text {, the ionization }(\mathrm{I}) \\
=\frac{\mathrm{N} \ln _{0} \mathrm{D}^{\prime}}{2 s}\{\sqrt{\mathrm{R}+d}-\sqrt{\bar{d}}\} .
\end{gathered}
$$

If we had here neglected the variation of ionization with velocity and supposed the ionization caused in traversing a distance $r$ to be proportional to $r$, we should have found that

$$
i \propto \frac{\mathrm{N} n_{0} \mathrm{D}^{\prime}}{s}\left(\mathrm{R}-\mathrm{D}+\frac{\mathrm{D}}{\mathrm{R}} \log \frac{1}{\mathrm{R}}\right) .
$$

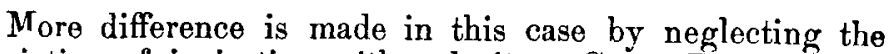
variation of ionization with velocity. Curve $B$ is plotted from the more accurate formula for the values $\mathrm{R}=7, d=1 \cdot 33$.

The curve is plotted from the following figures:-

$$
\begin{array}{|l|l|l|l|l|l|l|l|}
\mathbf{D} / \mathbf{R} \ldots & .061 & \cdot 124 & \cdot 250 & \cdot 357 & 500 & 690 & 8333 \\
i / \mathbf{I} \ldots \ldots & \cdot 807 & \cdot 672 & \cdot 467 & -335 & \cdot 193 & 077 & 023
\end{array}
$$


CASE (c). Layer of moderate thickness. - Let the air equivalent of the radioactive layer be $\mathrm{D}^{\prime}$.

This case must be considered in two parts :-

(a) When $r$ is such that $\mathrm{D}+\mathrm{D}^{\prime}+r<\mathrm{R}$ : the limits of $\theta$ being then $\cos ^{-1} \frac{\mathrm{D}+\mathrm{D}^{\prime}}{\mathrm{R}-r}$ and $\cos ^{-1} \frac{\mathrm{D}}{\mathrm{R}-r}$, and those of $r, 0$ and $\mathrm{R}-\mathrm{D}-\mathrm{D}^{\prime}$.

(b) When $r$ is such that $\mathrm{D}+\mathrm{D}^{\prime}+r \quad \mathrm{R}$, the limits of $\theta$ being then 0 and $\cos ^{-1} \frac{\mathrm{D}}{\mathrm{R}-r}$, and those of $r, 0$ and $\cos ^{-1} \mathrm{D}-r$.

Hence

$$
\begin{aligned}
i=\frac{\mathrm{N} l n_{0}}{4 s} & \int_{\mathrm{R}-\mathrm{D}-\mathrm{D}}^{\mathrm{R}-\mathrm{D}}\left\{1-\frac{\mathrm{D}^{2}}{(\mathrm{R}-r)^{2}}\right\}(\sqrt{r+d}-\sqrt{d}) d r \\
& +\frac{\mathrm{N} \ln n_{0}}{4 s} \int_{0}^{\mathrm{R}-\mathrm{D}-\mathrm{D}^{\prime}}\left\{\frac{\left(\mathrm{D}+\mathrm{D}^{\prime}\right)^{2}-\mathrm{D}^{2}}{(\mathrm{R}-r)^{2}}\right\}(\sqrt{r+\bar{d}}-\sqrt{\bar{d}}) d r .
\end{aligned}
$$

and

$$
\begin{aligned}
& \frac{4 s i}{\mathrm{~N} l n_{0}}=\frac{2}{3}(\mathrm{R}+d-\mathrm{D})^{\frac{3}{2}}-\frac{2}{3}\left(\mathrm{R}+d-\mathrm{D}-\mathrm{D}^{\prime}\right)^{\frac{3}{4}}-2 \mathrm{D}^{\prime} \sqrt{ } d-\mathrm{D} \sqrt{\mathrm{R}+d \cdots \mathrm{D}} \\
& +\left(\mathrm{D}+\mathrm{D}^{\prime}\right) \sqrt{\left(\overline{\mathrm{R}}+\bar{d}-\overline{\mathrm{D}}-\mathrm{D}^{\prime}\right.}+\frac{\mathrm{D}^{2}}{\sqrt{\mathrm{R}+d}} \log \sqrt{\overline{\mathrm{D}+\mathrm{D}^{\prime}}}(\sqrt{\mathrm{R}+d}+\sqrt{\overline{\mathrm{R}}+\overline{\mathrm{D}}(\overline{\sqrt{\mathrm{R}+d}})} \\
& -\frac{\mathrm{D}^{\prime 2}+2 \mathrm{DD}^{\prime}}{\sqrt{\mathrm{R}+d}} \log \frac{\sqrt{\mathrm{R}}\left(\sqrt{\mathrm{R}+d}+\sqrt{\mathrm{R}+d}-\overline{\mathrm{D}}-\overline{\mathrm{D}}^{\prime}\right)}{\sqrt{\mathrm{L}+\mathrm{D}^{\prime}}(\sqrt{\mathrm{R}+d}+\sqrt{\bar{d}})}
\end{aligned}
$$

Curve $\mathrm{C}$ shows the result of plotting this formula for the case when $\mathrm{R}=3 \cdot 5, \mathrm{D}^{\prime}=\cdot 5$, and $d=1 \cdot 33$.

The curve is plotted from the following figures:-

$$
\begin{array}{l|l|l|l|l|l|l|l|}
\mathrm{D} / \mathrm{R} . . . & \cdot 057 & \cdot 143 & \cdot 200 & .257 & 380 & .500 & 714 \\
\mathrm{i} / \mathrm{I} . . . . & \cdot 833 & \cdot 642 & \cdot 539 & .449 & \cdot 288 & \cdot 174 & \cdot 044
\end{array}
$$

\section{Part II.}

The apparatus employed was of the usual form, and very similar to that described by Rutherford ('Radioactivity,' 1905, p. 98). As shown in fig. 2, the material was laid on the high-potential plate $B$, at such a distance from the upper plate A that no a particle could reach it. Thus every a particle ran to its extreme range; and, to make more certain of catching all the ions, the upper plate was extended downwards at the sides. 
Uranium.

The uranium was used in the form of the green oxide, $\mathrm{U}_{3} \mathrm{O}_{8}$, and was freed for the time from UrX. This was not necessary, but convenient, as it diminished the $\beta$ ray correction.

Fig. 2.

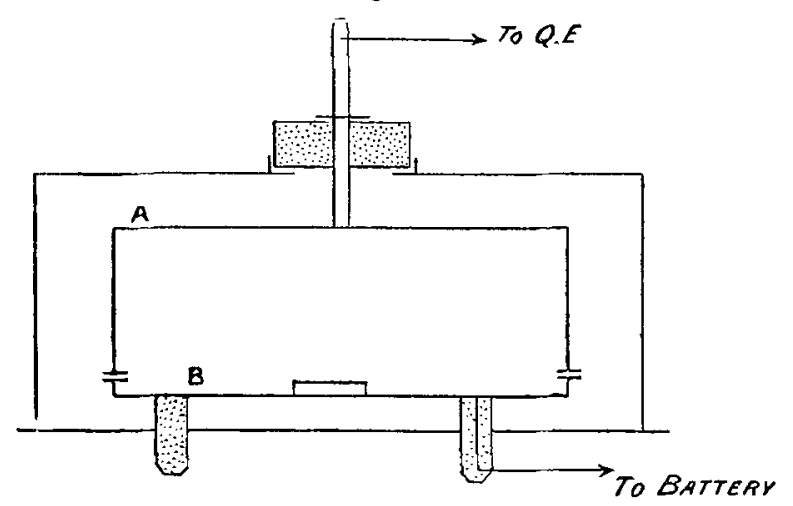

The uranium was ground to a fine powder and placed in a shallow depression turned in a metal plate, the diameter of the recess being $3 \cdot 17$ and the depth $\frac{1}{32}$ inch, which was far more than enough to make sure that the $\alpha$ rays from the lowest stratum could not get out. The surface of the material was carefully smoothed by the aid of a polished metal plate. A potential of 300 volts was used, which was nearly sufficient to saturate: more was not necessary, as only relative ionizations were in question. Aluminium-foil was used as the absorbing layer: the weight and area of each piece being measured so as to obtain the product of the density $(\rho)$ and the thickness $(d)$. In the following table (p. 762) the first column gives the value of $\rho d$ of the foil used, and the second the corresponding current, being the mean of five readings of the leak for ten seconds.

The last line shows that when two layers of tinfoil were added to the aluminium-foil already covering the uranium, the leak was reduced to 34. Each layer of foil was equivalent to about $17 \mathrm{~mm}$. of air, and the aluminium to about 21 ; so that the whole cut off the a rays completely, for their range was known to be not more than $3.5 \mathrm{~cm}$. This leak of 34 was therefore due to $\beta$ rays and the normal leak of the apparatus. The third column shows the result of subtracting 34 from all the figures of the second column and reducing to a decimal of $I$. The numbers so obtained have then been Phil. Mag. S. 6. Vol. 11. No. 66. June 1906. 3 D 


\begin{tabular}{|c|c|c|c|c|}
\hline $\begin{array}{c}\mathrm{I} . \\
\rho d \times 10^{8}\end{array}$ & $\begin{array}{l}\text { II. } \\
i .\end{array}$ & $\begin{array}{c}\text { III. } \\
i / \mathrm{I} .\end{array}$ & 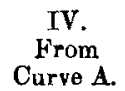 & $\begin{array}{c}\nabla . \\
\rho d \text { of full } \\
\text { range } \times 10^{5} \text {. }\end{array}$ \\
\hline 0 & 1044 & $1 \cdot 000$ & & \\
\hline 317 & 811 & 768 & $\cdot 0705$ & 448 \\
\hline 633 & 635 & $\cdot 595$ & $\cdot 139$ & 462 \\
\hline 949 & 494 & 456 & $\cdot 205$ & 463 \\
\hline 1265 & 376 & $\cdot 339$ & $\cdot 275$ & 460 \\
\hline 1620 & 275 & .239 & $\cdot 353$ & 458 \\
\hline 1930 & 201 & $\cdot 165$ & $\cdot 425$ & 455 \\
\hline 2610 & 97 & .062 & -580 & 449 \\
\hline $\begin{array}{c}3290 \\
+2 \text { layers } \\
\text { of tinfoil. }\end{array}$ & $\begin{array}{l}55 \\
34\end{array}$ & $\begin{array}{c}\cdot 021 \\
0\end{array}$ & .718 & 458 \\
\hline
\end{tabular}

considered as so many ordinates of the, thick-layer curve $A$; and the corresponding abscissæ found and placed in the fourth column. It was then possible to obtain from each reading a determination of the $\rho d$ of that aluminium sheet which the $\alpha$ particle of $\mathrm{Ur}$ could just penetrate. For example, the table shows that the sheet for which $\rho d=\cdot 000949$ is 20.5 per cent. of the necessary thickness, and so the $\rho d$ of the fully intercepting sheet is $\cdot 000949 / \cdot 205=\cdot 00463$. All these separate determinations are shown in the fifth column. Their close agreement with each other is good evidence of the truth of the formula used in obtaining them.

Taking 00456 as the mean of the figures in the last column, the final result may be thus stated:-

The a particle of uranium can just penetrate a sheet of aluminium for which $\rho d=\cdot 00456$.

Although this may at once be interpreted so as to give the range of the $\alpha$ particle in air, yet it is better to measure the ranges of radium and thorium also in terms of aluminium-foil.

\section{Radium.}

The application of this method to thorium and radium is somewhat more difficult than in the case of uranium, since it is necessary for success that the radioactive material should issue a particles of one range only. It might no doubt be possible to allow for the existence of other a particles if their range and relative number were known. Some method of this kind must doubtless be used for Th $\mathrm{X}$, and Th emanation. But it is obviously more direct, in the case of radium and thorium, to deal with the pure materials, if possible. 
A very small quantity of radium bromide was evaporated on a platinum plate, which was then raised to a bright red heat for some minutes. This freed the radium from emanation, $\mathrm{Ra} A$, and some $\mathrm{Ra} C$. The ionization current due to this plate fell off quickly; and in three hours was down to half its first value. The remaining $\mathrm{RaC}$ had then disappeared. It was reheated, to get rid of any fresh emanation; and it was then assumed that the great majority of the $a$ particles emitted from the plate were due to radium itself (Bragg \& Kleeman, Phil. Mag. Sept. 1905, p. 324).

The following table shows the result of experiment with the plate so prepared. The aluminiam-foils were the same as those used in the uranium experiments. The curve employed was of course not the same, since the layer was thin. According to the experiments of Kleeman and myself such a layer may be considered as equivalent to $5 \mathrm{~mm}$. of air. The results were therefore calculated from curve $\mathrm{C}$.

\begin{tabular}{|c|c|c|c|c|}
\hline $\begin{array}{c}\text { I. } \\
\rho d \times 10^{6}\end{array}$ & $\begin{array}{c}\text { II. } \\
i .\end{array}$ & $\begin{array}{l}\mathrm{III} . \\
i / \mathrm{I} .\end{array}$ & $\begin{array}{c}\text { IV. } \\
\text { From } \\
\text { Curve C. }\end{array}$ & $\begin{array}{c}\mathrm{V} . \\
\rho d \text { of full } \\
\text { range } \times 10^{5}\end{array}$ \\
\hline 0 & 1454 & 1.000 & & \\
\hline 317 & 1128 & 772 & 075 & 423 \\
\hline 633 & 927 & 634 & $\cdot 143$ & 443 \\
\hline 949 & 765 & .522 & .204 & 473 \\
\hline 1265 & 645 & $\cdot 426$ & $\cdot 265$ & 477 \\
\hline 1617 & 488 & $\cdot 331$ & $\cdot 343$ & 472 \\
\hline 1933 & 388 & $\cdot 261$ & $\cdot 407$ & 476 \\
\hline 2613 & 216 & $\cdot 150$ & $\cdot 532$ & 473 \\
\hline 3289 & 104 & 072 & $\cdot 675$ & 488 \\
\hline Tinfoil & 11 & 0 & & \\
\hline
\end{tabular}

These figures show an agreement between calculation and observation which is nearly as good as in the case of uranium. There is indeed a gradual increase in the figures of the last column; but such an effect should be expected, as there were present some $a$ particles of longer range than those of radium, but none of shorter range. Neglecting this effect, the mean of the results of the last column is 466 ; and we may take this to express the product of the thickness and density of that aluminium sheet which the $\alpha$ particle of radium can just penetrate, with the reservation that it is probably too high by a small but uncertain amount, the error being caused by a slight want of purity in the material used. This statement $3 \mathrm{D} 2$ 
applies only in considering the relative ranges of uranium and thorium; other considerations enter when the method is used to determine ranges absolutely.

The falling of the first two results in column $\mathrm{V}$. below the average of the column may in part be due to the fact that the first layer or two must cut off the easily absorbed radiation whose existence has been proved by J.J. Thomson and by Rutherford. I am not aware of any measurement of the amount of ionization due to this radiation. If in this experiment only 4 per cent. of the whole ionization current when the material is uncovered is supposed due to this cause, and if the foil whose $\rho d=\cdot 000317$ cuts off three quarters of it and the next addition of foil the remainder, then the figures in the last column become, in order, $488,487,487,496,486$, $490,502,514$. Thus the existence of a small quantity of radiation of this sort would explain the present discrepancies in the experiment. It will be seen later that a similar effect occurs with thorium. It is not so noticeable in the uranium experiment, as will be seen on turning back to the table of results. Still the first of these is rather smaller than the others; and a special measurement made with a very thin layer for which $\rho d=000133$ gave a value for the full range equal to 00426 , which is smaller still.

\section{$R a C$.}

As a further test of the method, I have used it to determine the range of the a particle of $\mathrm{RaC}$. The special difficulty in this case was due to the rapid decline of the activity. It was avoided by taking readings of the current due to the uncovered active plate before and after each measurement with the corered plate. The geometric mean of these was taken and compared with the smaller measurement. The readings were properly spaced in time, so as to make this correct. The leak due to $\beta$ rays and external causes was found by placing six sheets of tinfoil, each equivalent to about $15 \mathrm{~mm}$. of air, over the active plate. Tinfoil was used as the absorbing sheet. The results were as follows :-

\begin{tabular}{|c|c|c|c|}
\hline $\begin{array}{c}\text { I. } \\
\rho d \text { of tinfoil } \\
\times 10^{6}\end{array}$ & $\begin{array}{c}\text { II. } \\
i / \text { I. }\end{array}$ & $\begin{array}{c}\text { III. } \\
\text { From Curve B. }\end{array}$ & $\begin{array}{c}\text { IV. } \\
\rho d \text { of full range } \\
\times 10^{5} .\end{array}$ \\
\hline 479 & $\cdot 518$ & $34 \cdot 2$ & 224 \\
958 & .235 & $73 \cdot 0$ & 210 \\
1437 & .072 & $112 \cdot 5$ & 204 \\
\hline
\end{tabular}


The results are in rather better agreement with theory than the last column seems at first sight to show ; for the first and third observations fell on such points of the curve that errors of measurement were magnified in calculating the result. The second measurement has the greatest chance of being accurate, and is very nearly the mean of the three. An independent experiment showed that tinfoil for which $\rho d=$ .000536 was equivalent to $1.88 \mathrm{~cm}$. of air. Hence the range of the $a$ particle found by this method $=210 \times 1 \cdot 88 / 535=7 \cdot 4$. The value found by Kleeman and myself, using the direct and more accurate method, was $7 \cdot 1$ nearly.

\section{Thorium.}

The material was used in the form of thorium oxide which had been freed as far as possible from other radioactive substances by means of the processes described by Rutherford and Soddy. The treatment employed, which included heating to a bright red heat as the final stage, was judged to have been successful for the following reasons. In the first place, the recovery of activity was not marked by an initial drop, so far as could be observed : in the second, it rose at a rate which showed that it would be halfway to the final value in four days, the final value being about four times the initial. In the third place, no emanation came off the material when first prepared; even when no draught was einployed the readings did not alter in 15 minutes : and in the fourth place, the observed results fitted closely to the calculated curves, showing only a slight variation as in the case of the radium. table :-

The results of one experiment are shown in the following

\begin{tabular}{|c|c|c|c|}
\hline $\begin{array}{c}\text { I. } \\
\rho d \text { of } \Delta 1 \text { foil } \\
\times 10^{3} .\end{array}$ & $\begin{array}{c}\text { II. } \\
i / \text { I. }\end{array}$ & $\begin{array}{c}\text { III. } \\
\text { From Curve A. }\end{array}$ & $\begin{array}{c}\text { IV. } \\
\rho d \text { of full range } \\
\times 10^{5} .\end{array}$ \\
\hline 244 & $\cdot 813$ & $\cdot 055$ & 444 \\
474 & $\cdot 670$ & $\cdot 108$ & 439 \\
780 & $\cdot 544$ & $\cdot 162$ & 480 \\
1061 & $\cdot 412$ & $\cdot 227$ & 468 \\
1573 & $\cdot 271$ & $\cdot 328$ & 480 \\
2073 & $\cdot 173$ & $\cdot 417$ & 499 \\
2607 & $\cdot 106$ & $\cdot 504$ & 517 \\
\hline
\end{tabular}

The mean of the figures in the last column is $\cdot 00477$. 
In another experiment the thorium was precipitated twice at intervals of two days and then five times at intervals of 12 hours. The results were as follows :-

\begin{tabular}{|c|c|c|c|}
\hline $\begin{array}{c}\text { I. } \\
\rho d \text { of Al foil } \\
\times 10^{8} .\end{array}$ & $\begin{array}{c}\text { II. } \\
i / \text { I. }\end{array}$ & $\begin{array}{c}\text { III. } \\
\text { From Curve A. }\end{array}$ & $\begin{array}{c}\text { IV. } \\
\rho d \text { of full range } \\
\times 10^{5} .\end{array}$ \\
\hline 534 & -655 & -114 & 470 \\
1046 & $\cdot 425$ & -221 & 473 \\
1633 & $\cdot 248$ & .347 & 471 \\
2133 & $\cdot 154$ & .438 & 486 \\
\hline
\end{tabular}

In this case the mean of the figures in the last column is 00475 . As in the case of radium, this result is probably a little too high as it is impossible to get rid of all the radioactive products of thorium, and all these have ranges higher than thorium itself. For Rutherford has shown that the $a$ particle of the induced activity of thorium has the same penetrating power as the $\alpha$ particle of the induced activity of radium; and some rough experiments which I have made with $\mathrm{ThX}$ go to show that, as in the case of $\mathrm{Ra}$, the second and third active products have ranges intermediate between the first and fourth *

It may also be calculated from an experiment of Rutherford's ('Radioactivity' 2nd ed. p. 263) that the range of the emanation a particle is about $6 \mathrm{~cm}$.; but there is some uncertainty as to the stopping power of the mica sheet which he used.

The general conclusion is therefore that uranium, thorium, and radium eject $\alpha$ particles of nearly, if not exactly, the same speed. Considering the many parallelisms already known to exist between the processes of disintegration of these substances and their products, this new fact is certainly suggestive. It would be very interesting to know the ranges of Th $\mathrm{X}$ and Th emanation.

An expression is found in Part I. of this paper for the total ionization over an uncovered deep layer of active

* An experiment by Schmidt (Phys. Zeit. No. 25, p. 897) has shown that $\operatorname{RaA}$ has two-thirds of the penetrating power of Ra $C$. Hence its range must be the longer of the two intermediate ranges, determined by Kleeman and myself, viz. 4.83 ; and the range of the emanation must be 4.23. Thus in the radioactive sequence each explosion is more violent than the last. 
material. By its aid we may find the relative numbers of a particles emitted by uranium and thorium, when the ionization currents due to known areas of the layers have been measured. Since the ranges are so nearly alike, it is sufficient to use the simpler formula

$$
\mathrm{I}=\frac{\mathrm{N} l^{\prime} n_{0}}{8 s} \cdot \mathrm{R}^{2} .
$$

If now the suffixes $U$ and $T$ refer to uranium and thorium, we have

and therefore

$$
\frac{I_{\mathrm{V}}}{I_{\mathrm{T}}}=\frac{N_{\mathrm{U}} R_{\mathrm{U}}^{2} s_{\mathrm{T}}}{N_{\mathrm{T}} \mathrm{R}_{\mathrm{T}}^{2} s_{\mathrm{U}}}
$$

$$
\frac{N_{T}}{N_{U}}=\frac{T_{T} R_{U}^{2} s_{T}}{T_{U} R_{T}^{2} s_{U}}
$$

Each time that a thorium experiment was completed, a comparison was made of the currents $I_{T}$ and $I_{U}$. In the first case $I_{T} / I_{U}$ was found to be $\cdot 234$, in the second $\cdot 234$. $\left(R_{V} / R_{T}\right)^{2}$, as may be seen from the results given above, can be taken as equal to $(456 / 476)^{2}=\cdot 916$.

Also

$$
\frac{s_{\mathrm{T}}}{\mathrm{sU}_{\mathrm{U}}}=\frac{\sqrt{232}+2 \sqrt{16}}{\sqrt{239}+8 \sqrt{16}}=\frac{23 \cdot 2}{26 \cdot 2},
$$

assuming the square-root law (Bragg and Kleeman, Phil. Mag. Sept. 1905) to hold for uranium and thorium.

Hence tinally

$$
\begin{aligned}
\frac{\mathrm{N}_{\mathbf{T}}}{\mathrm{N}_{\mathrm{U}}} & =\cdot 234 \times \cdot 916 \times \frac{23 \cdot 2}{26 \cdot 2} \\
& =\cdot 190 .
\end{aligned}
$$

This result may be a little too small, since the range of the $\alpha$ particle of thorium may be slightly overestimated. The square of the range enters into the formula of comparison ; but on the otber hand, any a rays of long range which have not been removed from the thorium would make $I_{T}$ too large. On the whole, therefore, the actual value cannot be far from $\cdot 20 ; i$. e. the uranium atoms break down very nearly five times as fast as the thorium.

I have preferred to make the method one of comparison of ranges rather than of absolute determination. For there are two or three difficulties in using it for the latter purpose. In 
the first place, it is not easy to make the thin aluminium-leaf lie very close to the radiating surface; and the layers of air close to the surface contribute a relatively large number of ions. To make this error uniform I have used a net of very fine wires, with a mesh of $\frac{3}{8}$ of an inch to keep the foils down. Again, there is a disturbing effect due to the secondary ionization of the absorbing sheet. Mme. Curie has called attention to effects of this kind (Rutherford, 'Radioactivity,' 1905, p. 189). I find that there is slightly more ionization when, of two layers of foil, $\mathrm{Al}$ and $\mathrm{Sn}$, the latter is on top. Using tinfoil, the range always comes out rather larger than when aluminium-foil is employed. This may possibly be because the tinfoil lies closer to the surface. All these effects are small, and disappear in a comparison method.

By direct measurement $I$ found that aluminium-foil for which $\rho d=\cdot 00329$ was equivalent to $2 \cdot 30 \mathrm{~cm}$. of air. Hence the range of the $\alpha$ particle of radium as measured by this method $=2 \cdot 30 \times 466 / 329=3 \cdot 26$. The actual value, as found directly, is 3.54 .

One other difficulty lies in the way of a direct determination. As has already been mentioned bv Kleeman and myself (Phil. Mag. Sept. 1905), the loss of range of the a particle of $\mathrm{RaC}$ in going through a given sheet of material appears from the ionization curves to be slightly greater than the loss of an a particle of $\mathrm{RaA}$; and it is not quite clear whether this difference is real or apparent.

I owe my grateful thanks to Dr. W. T. Cooke who carried out for me all the necessary chemical operations.

Since the above was written $I$ have received the February number of the Philosophical Magazine containing an article by Mr. N. R. Campbell on "The Radiation from Ordinary Materials." In finding the formulæ necessary to his investigation, Mr. Campbell has anticipated part of the work in Part I. of this paper; but as the fuller treatment which I have given is required for my own experiment, $I$ have thought it better to allow it to stand without alteration.

In a footnote Mr. Campbell expresses his inability to understand why I inserted an obliquity factor $\cos \theta$ into the preliminary calculations in my first paper on the $\alpha$ rays (Phil. Mag. Dec. 1904). The mistake is mine. I did not discover it until I had occasion to reconsider the matter in connexion with the present investigation. 